\title{
Some Experiences with the Use of Arteriovenous Fistulae in Chronic Haemodialysis
}

\author{
R. PATEL,* M.B., M.R.C.P., M.R.A.C.P. ; I. LIDSKY,† M.D. ; V. VERTES, † M.D. \\ L. KEST,§ M.D.; S. COHEN,§ M.D.
}

Brtt. med.F., 1968, 1, 414-416

The discovery of an indwelling Silastic-Teflon cannula by Quinton et al. (1962) provided a convenient means of gaining access to the blood vessels for repeated haemodialysis. Frequent clotting, infection, and restricted use of the annulated extremity, however, are some of the major disadvantages of this technique (Ramirez et al., 1966). For this reason Brescia et al. (1966) sought the use of a surgically created subcutaneous arteriovenous fistula at the wrist as a substitute for the Silastic-Teflon cannula. In a subsequent communication Menno et al. (1967) reiterated the usefulness of the method and showed that cardiac status was not adversely affected. We describe here our experience with the use of arteriovenous fistulae in six patients over a period of 31 patient-months. A total of 253 dialyses were performed, necessitating over 550 venepunctures. In this paper particular reference is made to 100 consecutive dialyses for which adequate data are available and which were performed solely by the nurses using this technique.

\section{Materials and Methods}

Six of the 23 patients currently on the haemodialysis programme have arteriovenous fistulae. They are three women and three men aged 28 to 53 years (Table I). All have endstage renal disease and are maintained on biweekly haemodialysis with the Kolff twin-coil dialyser and a single pass central dialysate supply system (Patel et al., 1967). The duration of dialyses ranged from six to eight hours. One Negro man has had bilateral nephrectomy and is awaiting a cadaver transplant.

TABLE I.-Particulars of the Six Haemodialysis Patients with

\begin{tabular}{|c|c|c|c|c|}
\hline Case No. & Age & Sex & $\begin{array}{l}\text { Duration on } \\
\text { Programme } \\
\text { (Months) }\end{array}$ & No. of Dialyses \\
\hline $\begin{array}{l}1 \\
2 \\
3 \\
4 \\
5 \\
6\end{array}$ & $\begin{array}{l}40 \\
48 \\
47 \\
28 \\
53 \\
50\end{array}$ & $\begin{array}{c}F \\
\stackrel{F}{M} \\
F \\
F \\
\vec{M} \\
M\end{array}$ & $\begin{array}{l}5 \\
5 \\
3 \\
5 \\
8 \\
5\end{array}$ & $\begin{array}{l}30 \\
43 \\
31 \\
43 \\
62 \\
44\end{array}$ \\
\hline
\end{tabular}

Measurement of Blood Flow Rate.-Our modified twin-coil dialyser employed a Sarns roller pump (obtainable from Sarns Inc., Ann Arbor, Michigan) in place of the usual finger pump. Blood flow through a dialyser could be read off from a chart for any given pump speed, since the latter had been previously calibrated. With repeated checking the difference between paired readings ranged from 0 to $8 \mathrm{ml}$./minute. Furthermore, the results were in close agreement with those obtained by the bubble transit technique when used for comparison in one patient. To estimate the maximum blood flow (with or without

\footnotetext{
- Physician-in-Charge, Dialysis Unit. Present address : Department of Surgery, Centre for Health Sciences, University of California, Los Angeles, California. † Consultant Surgeon. Director, Division of Medicine. Urologist.

The Dialysis Unit, and the Divisions of Medicine and Surgery, Mount Sinai Hospital of Cleveland, Cleveland, Ohio, U.S.A.
}

a tourniquet), the pump speed was increased stepwise to a point beyond which further increase would cause a suction collapse of the dialyser inflow tubing resulting in an abrupt fall in the blood flow.

Surgical Technique.-A fistula is created between the radial artery at the wrist and the largest adjacent vein. Longitudinal incisions ( $7 \mathrm{~mm}$. long) are made in the artery and the vein, and the edges are approximated with fine sutures, resulting in a 5-mm. fistula. A thrill is felt immediately or within a few hours.

Technique of Venepuncture.-Initially all venepunctures were performed by the physician, but the task has now been delegated to the registered nursing staff, and the physician is called on only in cases of difficulty. Venepunctures into the dilated superficial veins (Fig. 1) are performed with two 2-in. $(5-\mathrm{cm}$.) long 14-gauge needles (obtainable from Deseret Pharmaceuticals Co., 19E Oakland Avenue, Salt Lake City, Utah) under infiltrative anaesthesia. A tourniquet is applied and a "venous" or dialyser outflow needle is inserted proximally in the forearm. Heparinized saline (4,000 units/litre) is dripped through the needle while the "arterial" or dialyser inflow needle is inserted into the distal forearm. Venepuncture too close to the fistula site is generally avoided lest an accidental haematoma results in its obliteration. The needles are taped in position and connected to the appropriate dialyser tubings (Fig. 2). At the end of the dialysis the needles are removed and firm pressure is applied over the puncture sites for 15 minutes. Light-pressure dressings are applied before discharge, and these are removed on the following morning.

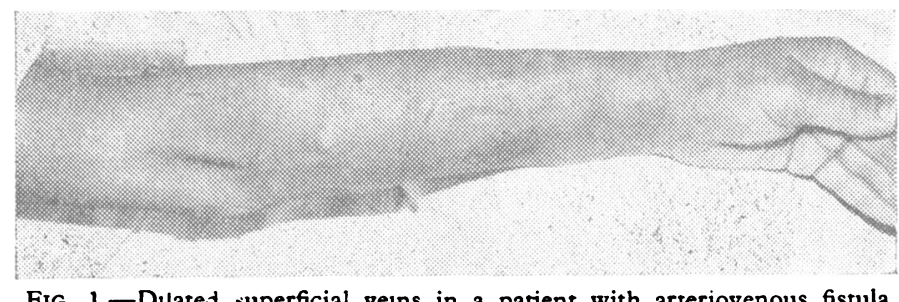

FIG. 1.-Dilated superficial verns in a patient with arteriovenous fistula.

Heparinization.-Intermittent systemic and regional heparinization is done according to the method previously described (Patel and Vertes, 1967).

\section{Results}

Patient's Response.-All six patients have expressed satisfaction with their fistulae and none is desirous of the cannula. They all feel relieved at not having to worry constantly about clotting and infection, so common with the cannula. All enjoy the freedom to use the arm ; to bathe, shower, or swim without fear. The women prefer it from a cosmetic point of view, though one has admitted that the distended veins make her arm "look like a man's." Two patients have admitted that the affected arm feels warmer than its fellow.

Staff Response.-In contrast, the nursing staff in general prefers the cannula to the fistula. They have expressed fear of 
causing possible pain during venepuncture, of "something going wrong" and delaying the start of dialysis, of accidental haematoma formation, and of the needle becoming dislodged from the vein during dialysis.

\section{Analysis of 100 Consecutive Nurse-performed Venepunctures}

Time Factor.-In our unit a registered nurse performs the venepunctures and attaches the patient to the dialyser by herself. Table II shows the time taken from the start of the venepuncture to the start of dialysis. In $70 \%$ dialysis was under way within 15 minutes. This compares favourably with the time taken with the cannulated patients, in whom time is expended during the preliminary cleansing of the shunt area. Delay occurred when needles were improperly placed, with resultant poor blood flow, when haematoma formed, and rarely when a needle became thrombosed. In no instance was dialysis postponed because of difficulty with venepuncture.

TABLB II.-Time Involved in Starting Dialysis in a Patient with Fistula

\begin{tabular}{|c|c|c|c|c|c|}
\hline $\begin{array}{l}\text { No. of dialyses ... } \\
\text { Time in minutes }\end{array}$ & .. & $\begin{array}{c}70 \\
5-15\end{array}$ & $\begin{array}{c}15 \\
16-20\end{array}$ & $\underset{21-30}{6}$ & $\stackrel{9}{9}$ Over 30 \\
\hline
\end{tabular}

Physician Assistance.-In the 100 dialyses performed by the nurses direct intervention by the physician was required in 21 instances. In most of these assistance was sought with the "arterial" venepuncture. Assistance was mostly requested in the early phase of nurse training, and in fact was called for only once in the last 28 dialyses, and then for minor advice.

Number of Venepunctures.-Each dialysis necessitates inserting two needles, an "arterial" and a "venous." In the 100 dialyses 243 venepunctures were done. Of the additional 43 venepunctures 15 were venous reinsertions due to the needle clotting during dialysis. The remainder were either arterial or venous reinsertions because of haematoma formation, poor blood flow, and, rarely, clotting within the arterial needle. Of the 15 episodes of clotting within the venous needle during dialysis 12 occurred in one man despite a Lee-White clottingtime in excess of an hour. Increased heparin dose and use of siliconized needles have largely overcome this problem.

\section{Complications}

Haematoma Formation.-Minor ecchymoses were not uncommon, but haematoma exceeding $1 \mathrm{in}$. in diameter occurred in only four instances.

Clotting.-Needle-clotting during dialysis is virtually confined to the low-pressure venous needle. It occurred particularly often during early dialyses. Interestingly, 12 of the 15 such episodes referred to above occurred in a Negro man. This is consistent with W. J. Kolff's observation (personal communication) that some patients (the so-called "clotters") are particularly vulnerable to clotting episodes. This is also favoured by the findings of Erickson et al. (1966) in such patients of significantly higher levels of clotting factors as compared with those patients who manifest fewer clotting episodes. We have been able to overcome this by using a larger heparin dose and having the needles siliconized. We have not had any experience with long-term anticoagulation in these patients. Arterial clotting has not occurred during dialysis though a reinsertion had to be done when an arterial needle became thrombosed during a venepuncture.

Needle Position.-A major factor affecting flow through the needles is their position within the veins. Malpositioned needles result in suction trapping of the vessel wall against the needle bevel, which can often be seen and felt through the skin. This may cause an abnormal elevation of the coil outlet pressure or a poor blood flow through the dialyser, depending on whether the venous or the arterial needle is involved. For this reason tortuous segments of veins are avoided and the needle is inserted to the hilt whenever possible. Needles are taped only after their optimum positions are ascertained by manipulation.

Dislodgement of Needles.-This occurred in two instances in a restless and nervous patient when the dialyser outflow tubing became disconnected from the needle.

Bleeding After Dialysis.-Bleeding from the needle puncture sites is generally easily controlled by firm pressure for 10 minutes. In the occasional difficult case uniform pressure exerted over the puncture site by means of a sphygmomanometer cuff distended to a pressure midway between systolic and diastolic almost always controls the bleeding within a few minutes. In rare instances protamine might be needed to neutralize the heparin. In only one instance did bleeding recur at home from an arterial pressure site, and this was easily controlled by the patient with local pressure.

Infections.-Local or systemic infections have not occurred despite a total of over 550 venepunctures. Pain during dialysis has not been a problem.

Efficiency.-Efficiency of a fistula can be judged by the adequacy of blood flow and by chemical and clinical results in the patients.

\section{Blood Flow Rate}

A blood flow rate between 200 and $350 \mathrm{ml} . / \mathrm{min}$. has been obtained through the fistula. Flow can be increased significantly by light application of a rubber tourniquet between two needles. In only three instances was a blood flow of less than $200 \mathrm{ml} . /$ min. obtained that could not be improved on by a tourniquet.

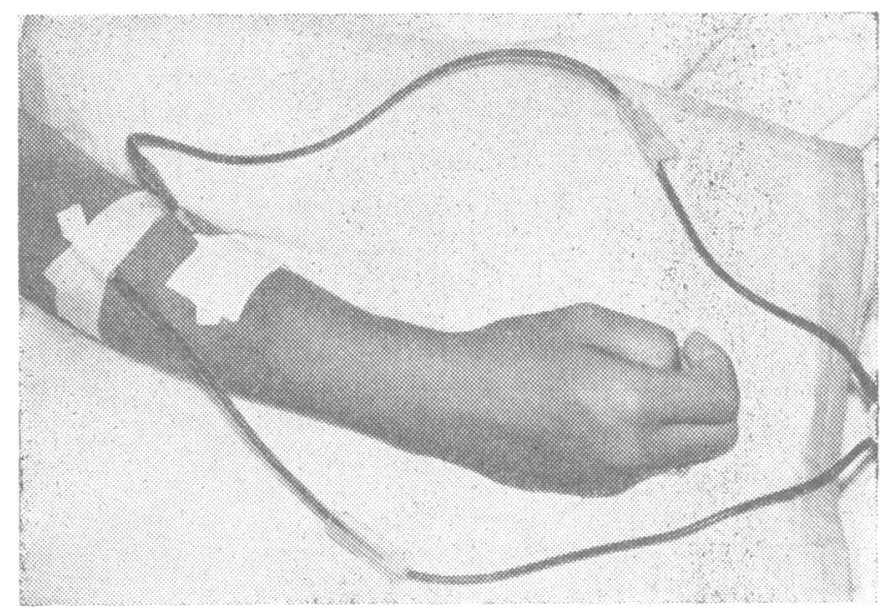

FIG. 2.--Showing the positions of needles during haemodialysis.

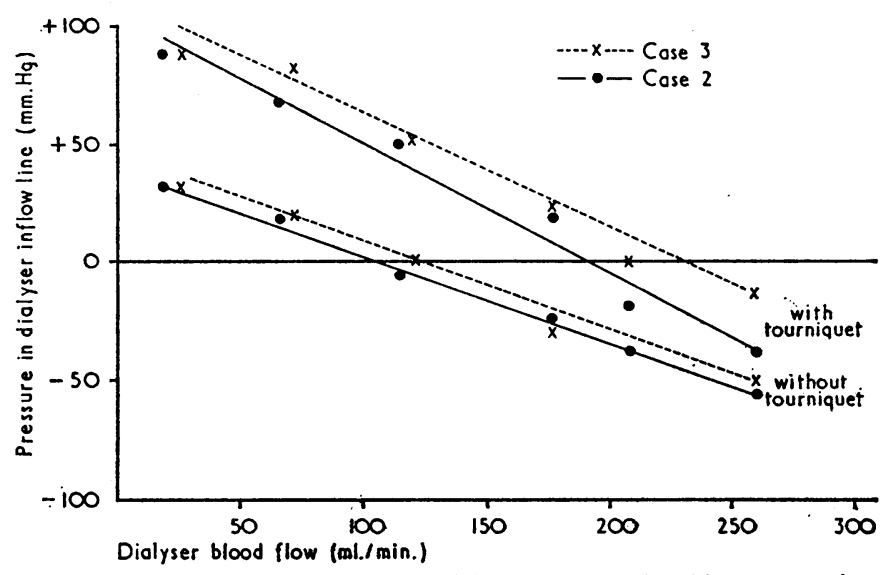

FIG. 3.-Pressure changes in the dialyser "inflow" tubing at varying blood flow rates in two patients with arteriovenous fistulae. 
Blood is drawn into the twin coil by a positive propulsive pressure within the vein aided by a negative suction pressure exerted by the dialyser pump. The relation between the blood flow and pressure changes in the arterial tubing is of interest and is shown in Fig. 3. It can be seen that without a tourniquet, at flow rates below $100 \mathrm{ml}$./min., there is a net positive pressure of up to $25 \mathrm{~mm}$. Hg. At flow rates between 100 and $120 \mathrm{ml} . / \mathrm{min}$. there is a net zero pressure when presumably the positive venous pressure is balanced by the negative suction. pressure of the pump. At flows above this a net negative pressure prevails. At higher flows this increased suction pressure tends to collapse the vein on the needle, with an abrupt reduction of the dialyser blood flow. On application of a tourniquet there is an increase in positive pressure at a given flow rate, and zero pressure is not reached until a flow rate of $185-225 \mathrm{ml} . / \mathrm{min}$. is achieved. This higher pressure within the vein tends to prevent a suction collapse of the vein, thus accounting for the improved blood flow with the tourniquet.

\section{Chemical Results}

Table III compares the average pre- and post-dialysis blood urea nitrogen and creatinine in the six fistula patients with nine cannulated patients of similar age and weight. The results are comparable.

Turs III.-Pre- and Post-dialysis Chemistry of Pistulas and Cannoulated Patients

\begin{tabular}{|c|c|c|c|c|c|c|}
\hline \multirow{2}{*}{ Croe } & \multirow{2}{*}{$\begin{array}{l}\text { Creatinine } \\
\text { Clearance } \\
\text { (mi./min.) }\end{array}$} & \multicolumn{2}{|c|}{$\begin{array}{l}\text { Mean B.U.N. } \\
\text { (mg./100 m.) }\end{array}$} & \multicolumn{2}{|c|}{$\begin{array}{l}\text { Mean Creatinine } \\
\text { (ms./100 ml.) }\end{array}$} & \multirow{2}{*}{$\begin{array}{l}\text { No. of } \\
\text { Dialyses }\end{array}$} \\
\hline & & Pre & Post & Pre & Post & \\
\hline \multicolumn{7}{|c|}{ Firsula Patients } \\
\hline $\begin{array}{l}1 \\
2 \\
8 \\
5 \\
5 \\
6\end{array}$ & $\begin{array}{c}1.3 \\
0.52 \\
2.8 \\
0.9 \\
\text { Anephric } \\
0.7\end{array}$ & $\begin{array}{r}91 \\
72 \\
79 \\
81 \\
118 \\
104\end{array}$ & $\begin{array}{l}30 \\
33 \\
29 \\
26 \\
57 \\
47\end{array}$ & $\begin{array}{l}10 \\
11 \\
8 \\
10 \\
20 \\
14\end{array}$ & $\begin{array}{r}4 \\
6 \\
4 \\
5 \\
10 \\
7\end{array}$ & $\begin{array}{l}30 \\
43 \\
31 \\
43 \\
62 \\
44\end{array}$ \\
\hline \multicolumn{7}{|c|}{ Canmulared Patients } \\
\hline $\begin{array}{l}\mathbf{A} \\
\mathbf{B} \\
\mathbf{C} \\
\mathbf{D} \\
\mathbf{B} \\
\mathbf{D} \\
\mathbf{O} \\
\mathbf{H} \\
\mathbf{I}\end{array}$ & $\begin{array}{l}0.3 \\
0.5 \\
2.0 \\
0.56 \\
0.2 \\
0.17 \\
0.15 \\
0.34 \\
2.3\end{array}$ & $\begin{array}{r}103 \\
83 \\
66 \\
69 \\
94 \\
87 \\
92 \\
93 \\
74\end{array}$ & $\begin{array}{l}32 \\
30 \\
26 \\
31 \\
29 \\
35 \\
35 \\
38 \\
23\end{array}$ & $\begin{array}{l}16 \\
15 \\
13 \\
11 \\
14 \\
11 \\
13 \\
13 \\
11\end{array}$ & $\begin{array}{l}7 \\
7 \\
6 \\
6 \\
6 \\
6 \\
6 \\
7 \\
5\end{array}$ & $\begin{array}{l}88 \\
80 \\
70 \\
70 \\
90 \\
60 \\
50 \\
50 \\
60\end{array}$ \\
\hline
\end{tabular}

\section{Clinical Results}

The clinical results in general are satisfactory. The complications encountered were: neuropathy in one patient, hyperparathyroidism in one, and psychiatric in one; there were no complications in three patients. One woman has asymptomatic secondary hyperparathyroidism, and another has a moderately severe mixed neuropathy. All are normotensive. Two housewives are fully rehabilitated in that they are able to do all they did before their illness. Another housewife is working parttime at her previous secretarial job though she is somewhat handicapped by persistent paraesthesiae of the feet. One man capable of full-time employment is a part-time factory worker merely because of the time lost during the biweekly daytime dialysis. A second man is expected to start work later this month. Only one patient is disabled from a severe anxiety state and unable to work.

\section{Comment}

In general we are fully satisfied with our results with the arteriovenous fistula. The main advantages of a fistula are its preference by the patient, and the absence of certain complications that occur with the cannula. None of the fistulae have clotted, and infections have not occurred. The patients enjoy the freedom that cannulated patients do not. The women in particular prefer the less obvious cosmetic disability that is associated with having a fistula. Of considerable importance in rehabilitation is the observation that heavy work can be undertaken by men with anteriovenous fistulae in contrast to those with Silastic-Teflon cannulae. Our results also suggest that venepuncturing could be delegated to the trained nurses, and indeed our nurses feel confident that further experience will make them more adept with the technique. The clinical and chemical results are comparable to those obtained with the cannula. There has been no shortage of veins in any of the patients. It is noteworthy that all three women have excellent fistulae, a fact which has dispelled our earlier fears about the efficiency of the fistula in female patients who have vessels of smaller calibre. A point against the arteriovenous fistula is that it cannot be used with artificial kidneys other than those employing pumps. Despite the low resistance typical of other flat plate kidneys, we were unable to obtain any blood flow through the eight-layer Skeggs-Leonard kidney when dialysis was attempted in patients with arteriovenous fistulae.

We are encouraged by our results to date, and further fistulae are planned in additional patients accepted to the programme.

\section{Summary}

The use of arteriovenous fistulae in six patients on long-term haemodialysis is reported. The clinical and chemical results are comparable to those obtained with the Silastic-Teflon cannula. Results in 100 consecutive dialyses suggest that the performance of venepunctures could be satisfactorily delegated to the trained nursing staff. Complications encountered with the use of arteriovenous fistulae during haemodialysis are described.

We would like to thank the nursing staff of the Dialysis Unit for their skilful assistance.

\section{REFERENCBS}

Brescia, M. J., Cimino, J. E., Appel, K., and Hurwich, B. J. (1966). New Engl. 7. Med., 275, 1089.

Erickson, R. V., Williman, M., and Pendras, J. P. (1966). Trans. Amer. Soc. artif. intern. Organs, 12, 205.

Menno, A. D., Zizzi, J., Hodson, J., and McMahon, J. (1967). Ibid., 13, 62.

Patel, R., and Vertes, V. (1967). N.Z. med. 3., 66, 471. intern. Organs, 13, 5.

Quinton, W. E., Dillard, D. H., Cole, J. J., and Scribner, B. H. (1962). Ibid., 8, 236 .

Ramirez, O., Swartz, C., Onesti, G., Mailloux, L., and Brest, A. N. 